\title{
INVESTIGATION OF PHOTOELECTRIC CONVERTERS WITH A BASE CADMIUM TELLURIDE LAYER WITH A DECREASE IN ITS THICKNESS FOR TANDEM AND TWO-SIDED SENSITIVE INSTRUMENT STRUCTURES
}

\author{
Natalya Deyneko \\ Scientific department of problems of civil protection and technogenic and ecological safety of \\ the scientific and research center ${ }^{l}$ \\ natalyadeyneko@gmail.com \\ Igor Kryvulkin \\ Design and Technology Institute of Micrographics \\ 1/60 Akademika Pidhornoho lane, Kharkiv, Ukraine, 61046 \\ Mykola Matiushenko \\ Department of Information technologies design \\ Kharkiv National Technical University Kharkiv Polytechnic Institute" \\ 2 Kyrpychova str., Kharkiv, Ukraine, 61002 \\ Olexandr Tarasenko ${ }^{l}$ \\ Igor Khmyrov \\ Department of Supervision and Prevention ${ }^{l}$ \\ Anastasiia Khmyrova \\ Department of correspondence and distance learning ${ }^{l}$ \\ Roman Shevchenko \\ Scientific department of problems of civil protection and technogenic and ecological safety of the \\ scientific and research center ${ }^{l}$ \\ ${ }^{1}$ National University of Civil Defence of Ukraine \\ 94 Chernyshevska str., Kharkiv, Ukraine, 61023
}

\begin{abstract}
Photovoltaic cells with a base layer of cadmium telluride with a decrease in its thickness are studied. It is known that the widespread use of photovoltaic converters is constrained by their high price in the case of highly efficient instrument structures, or low efficiency. The creation of tandem and two-sided sensitive photoelectric converters will reduce their cost while increasing their efficiency. However, to create tandem and two-sided sensitive photoelectric converters, the necessary conditions are the use of transparent contacts and a decrease in the thickness of the base layer for efficient absorption of incident radiation by the converter, which is lower. In the research process, it was found that reducing the thickness of the base layer to $1 \mu \mathrm{m}$ allows to increase the efficiency of the photoelectric transducer during irradiation from the back. An increase in the efficiency of the photoelectric converter occurs due to a decrease in the distance from the generation region of nonequilibrium charge carriers in the region of separation. If the thickness of the base layer is less than $1 \mu \mathrm{m}$, then regardless of which side of the irradiation is carried out, a decrease in the efficiency of the instrument structure is observed. Increase in the efficiency of photoconverters is associated with an increase in the negative influence of recombination processes on the back contact, a decrease in the number of charge carriers generated due to incomplete absorption of incident radiation, and a decrease in the volume of the built-in field of the separating barrier when it overlaps with the depletion region of the back contact. ITO/CdS/CdTe/Cu/ITO SCs with a base layer thickness of $1 \mu \mathrm{m}$ demonstrates degradation stability. The highest value of efficiency in the case of illumination from the front side $8.1 \%$ and with illumination from the back side $3.8 \%$ received after a year of operation of the photovoltaic converter.
\end{abstract}

Keywords: cadmium telluride, photovoltaic converters, tandem and two-sided sensitive instrument structures.

DOI: $10.21303 / 2461-4262.2019 .001002$

\section{Introduction}

Today, advances in the production of high-performance photovoltaic converters are very successful. However, the massive use of such instrument structures is not observed. This is due, 
first of all, to the fact that the high efficiency of photoconverters is achieved by using complex heterostructures. Such instrument structures are expensive because they are created using precious high-tech equipment. However, the creation of photoconverters based on thin films from a wide variety of materials and compounds is a promising direction in the development of solar energy. Unfortunately, the efficiency of these photoconverters is not yet high enough, but the cost of equipment for their creation, and hence the cost of instrument structures, is already quite acceptable. So there are two directions for increasing the use of solar energy - increasing the efficiency and spectral sensitivity of photoconverters and reducing their cost.

The experimental values of the efficiency of photoconverters based on thin films differ significantly from theoretical ones. This circumstance is associated with energy losses due to the design features of photoelectric converters and the features of photoelectric processes that occur in the volume of the instrument structure when irradiated with sunlight $[1,2]$. A radical way to increase the efficiency of solar cells is the formation of tandem (cascade) [3] and two-sided sensitive structures that use two or more base layers with different $E_{g}$ (band gap). This approach allows to effectively convert incident solar radiation in a wide spectral range. The most interesting elements for the formation of tandem structures are film PECs based on CdTe and CuInSe ${ }_{2}$ [4]. It is known that $E_{g}$ for CdTe is $1.46 \mathrm{eV}$ [5], and $E_{g}$ is $1.10 \mathrm{eV}$ [6]. The combination of the energy structure of such solar cells will provide increased efficiency, both in terrestrial and in atmospheric conditions. However, the formation of tandem and two-sided sensitive instrument structures using solar cells with a CdTe base layer is constrained by two reasons. Firstly, the lack of effective transparent back contacts. Secondly, the thickness of the PEC base layer, which must be reduced.

The problem of creating transparent rear contacts to p-CdTe was considered in [7] and solved and described in detail in [8,9]. The authors of [9] studied the conditions for the creation and operation of $\mathrm{Cu} / \mathrm{ITO}$ transparent back contacts for film photoconverters with a CdTe base layer, which are intended for use in tandem and two-sided sensitive instrument structures.

Given the foregoing, it becomes relevant to study the method of creating PEC with a thin base layer of CdTe, which can be used in tandem and two-sided sensitive structures.

The aim of this research is the creation and study of solar cells with a thin base layer of CdTe suitable for use in tandem and two-sided sensitive structures.

To achieve this aim it is necessary to solve the following objectives:

1. To study the effectiveness of ITO/CdS/CdTe/Cu/ITO SCs with a decrease in the thickness of the base layer.

2. To study the effectiveness of ITO/CdS/CdTe/Cu/ITO SCs with a thin base layer when changing the direction of illumination.

3. To study degradation stability of the ITO/CdS/CdTe/Cu/ITO SCs with a thin base layer.

\section{Materials for the creation and methods of investigation of film photovoltaic cells with a base layer of CdTe}

2. 1. Materials and equipment used to obtain ITO/CdS/CdTe/Cu/ITO photoelectric converters

For research, a series of SC was made with a base layer thickness (hereinafter referred to as $t_{b l}$ ) from $2.5 \mu \mathrm{m}$ to $0.8 \mu \mathrm{m}$. The studied instrument structures ITO/CdS/CdTe/Cu/ITO were obtained by thermal evaporation using a UVN67 vacuum unit with modified internal equipment, the design of the units is given in [9]. Formed samples of ITO/CdS/CdTe were subjected to "chloride" treatment [10]. To carry out the "salt" treatment procedure, $\mathrm{CdCl}_{2}$ films were deposited on the CdTe surface without heating the substrate by thermal evaporation at a pressure of $10^{-5} \mathrm{~mm}$. During the "chloride" treatment, the $\mathrm{CdCl}_{2}$ layer linearly decreased from $0.35 \mu \mathrm{m}$ to $0.15 \mu \mathrm{m}$ with a decrease in the CdTe layer from $2.5 \mu \mathrm{m}$ to $0.8 \mu \mathrm{m}$. After the "salt" treatment, ITO/CdS/CdTe $/ \mathrm{CdCl}_{2}$ was annealed in air in a closed volume. Annealing in air was carried out at a temperature of $430{ }^{\circ} \mathrm{C}$ for 25 minutes. The annealing time was also linearly reduced from 25 minutes to 15 minutes with a decrease in the thickness of the base layer, and the thickness of the copper layer was reduced to $0.3 \mu \mathrm{m}$.

The ITO films (indium and tin oxides) were deposited by direct current non-reactive magnetic sputtering in a VUP-5M vacuum unit using an original material-saving magnetron [11]. The 
length of the discharge gap, which is the distance between the magnetron and the substrate, was $70 \mathrm{~mm}$. The power consumption of the magnetron was $0.2 \mathrm{~W} / \mathrm{cm}^{2}$. The substrate temperature $\left(T_{s}\right)$ was $300{ }^{\circ} \mathrm{C}$. The initial pressure in the vacuum chamber was $3 \times 10^{-5} \mathrm{~mm} \mathrm{hg}$., the working pressure of the argon-air mixture during the spraying process is $(2.1-2.6) \times 10^{-2} \mathrm{~mm}$. For pressing ITO targets, containing $95 \mathrm{wt}$. \% of indium oxide and $5 \mathrm{wt}$. \% of tin oxide a special press was made. It should be noted that magnetron sputtering is an effective method for producing all transparent electrodes [12, 13]. This is due to the high degree of accuracy of transferring the target composition to the substrate, reproducibility and controllability of the magnetron sputtering process $[14,15]$.

\section{2. Methods of measurement and analytical processing of light current-voltage char-} acteristics

Measurements of light current- voltage characteristics (hereinafter referred to as CVC) during the simulation of solar radiation by a system of LEDs were carried out according to the procedure described in [15].

The initial parameters and light diode characteristics (hereinafter referred to as LDC) of the studied samples were determined by their CVC obtained experimentally. The analytical processing of the light CVC of the investigated PECs was carried out using a PC.

The theoretical expression for describing the relationship between the efficiency of the PEC with light diode characteristics has the form:

$$
J_{\mathrm{n}}=-J_{p h} J_{0}\left\{\exp \left[e\left(V_{n}-J_{n} R_{s h}\right) /(A k T)\right]-1\right\}+\left(V_{n}-J_{n} R_{s h}\right) / R_{s}
$$

where $J_{n}$ - the current density; $J_{p h}$ - the photocurrent density; the saturation diode current density; $e$ - the electron charge; $V_{n}$ - voltage drop at the load; $R_{s h}$-series resistance; $A$ - the diode ideality coefficient; $k$ - the Boltzmann constant, $T$ - the temperature of the photoelectric converter; $R_{s}-$ shunt resistance.

According to the program, the analytical expression (1) for the light CVC turns into an expression, which has the form:

$$
\begin{gathered}
I_{n}=A_{0}-A_{1} V_{n}-A_{2} \exp \left(\mathrm{A}_{3} V_{n}+A_{4} I_{n}\right), \\
\left.A_{0}=\left(I_{p h}+I_{0}\right) R_{s} / R_{s h}+R_{s}\right), \\
A_{1}=1 /\left(R_{s h}+R_{s}\right), \\
A_{2}=I_{0} R_{s} /\left(R_{s h}+R_{s}\right), \\
A_{3}=e /(A k T), \\
A_{4}=e R_{s h} /(A k T) .
\end{gathered}
$$

Using expression (2) and experimentally obtained values of In and $V_{n}$, by varying the values of the above coefficients $A_{0}, A_{1}, A_{2}, A_{3}, A_{4}$, the best approximation of the experimental data is obtained, $I_{n}=I_{n}\left(V_{n}\right)$, described by the transformed theoretical expression (2). Usually, during analytical processing, the average deviation does not exceed $10^{-8}$, which corresponds to a relative error in the determination of the initial parameters and LDC at a level of no more than $1 \%$. After finding the specified coefficients that provide the best approximation, the initial PEC parameters are determined: $J_{s c}$ (current density short circuit), $V_{o c}$ (open circuit voltage), $F F$ (filling factor), $P_{m}$ (maximum power), Efficiency (coefficient of performance). LDC (light diode characteristics) $R_{s}$ (series resistance), $R_{s h}$ (shunt resistance), $A$ (diode ideality coefficient) and $J_{0}$ (saturation diode current density) are calculated according to the found coefficients $A_{0}, A_{1}, A_{2}, A_{3}, A_{4}$, using the relations (3)-(7) [16-18]. The error in determining the initial parameters and LDC is determined not only by the value of the standard deviation, but also by the error in the measurement of the light CVC. 


\section{Results of the study of experimental samples ITO/CdS/CdTe/Cu/ITO}

3. 1. Results of the study of changes in the output parameters and diode characteristics of the ITO/CdS/CdTe/Cu/ITO PECs at different thicknesses of the base layer

In this work, the CVCs of the instrument structures were measured upon irradiation on both sides with a change in the values of tbsh from $2.5 \mu \mathrm{m}$ to $0.8 \mu \mathrm{m}$. It was found that with a decrease in the thickness of CdTe films, one can distinguish characteristic thicknesses in which a change in the physical mechanisms of the influence of the distance from the back contact to the separating barrier on the efficiency of photoelectric processes in the base layer is observed (Fig. 1).

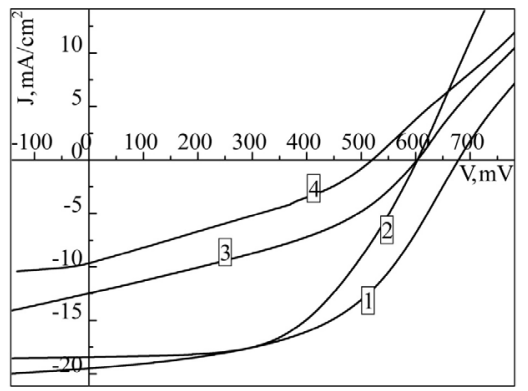

Fig. 1. Light CVCs of the solar cell: 1 - with a base layer thickness of $1 \mu \mathrm{m}$ and irradiation from the front side; 2 - with a base layer thickness of $0.8 \mu \mathrm{m}$ and irradiation from the front side; 3 - with a base layer thickness of $1 \mu \mathrm{m}$ and radiation from the back side; 4 - with a base layer thickness of $0.8 \mu \mathrm{m}$ and radiation from the back side

By analytical processing of the light CVCs, the initial parameters were obtained and the diode characteristics under irradiation on both sides were calculated. The output parameters and the LDC of the samples under irradiation on both sides are given in Tables 1, 2, respectively.

Table 1

$\mathrm{ITO} / \mathrm{CdS} / \mathrm{CdTe} / \mathrm{Cu} / \mathrm{ITO}$ output parameters and LDC of PEC upon irradiation from the front side

\begin{tabular}{|c|c|c|c|c|c|c|c|c|c|}
\hline $\begin{array}{l}\text { The thickness of } \\
\text { the base layer, } \mu \mathrm{m}\end{array}$ & $\begin{array}{c}J_{s c}, \\
\mathbf{m A} / \mathbf{c m}^{2}\end{array}$ & $\begin{array}{l}V_{o c}, \\
\mathbf{m V}\end{array}$ & FF & $\begin{array}{c}\text { Efficiency, } \\
\%\end{array}$ & $\begin{array}{c}J_{p}, \\
\mathbf{m A} / \mathbf{c m}^{2}\end{array}$ & $\begin{array}{c}R_{s h}, \\
\mathrm{Ohm} \cdot \mathrm{cm}^{2}\end{array}$ & $\begin{array}{c}R, \\
\mathrm{Ohm} \cdot \mathrm{cm}^{2}\end{array}$ & $A$ & $\begin{array}{c}J_{0}, \\
\mathbf{A} / \mathbf{c m}^{2} \\
\end{array}$ \\
\hline 2,5 & 19,4 & 740 & 0,68 & 9,8 & 19,5 & 1,6 & 1031 & 2,28 & $6.2 \cdot 10^{-8}$ \\
\hline 1 & 19,3 & 670 & 0,52 & 6,7 & 19,7 & 4 & 185 & 3,03 & $3,0 \cdot 10^{-6}$ \\
\hline 0,8 & 19,1 & 607 & 0,51 & 5,9 & 19,2 & $<0,1$ & 169 & 4,11 & $4,9 \cdot 10^{-5}$ \\
\hline
\end{tabular}

Table 2

ITO/CdS/CdTe/Cu/ITO PECs output parameters and LDC upon irradiation from the back side

\begin{tabular}{|c|c|c|c|c|c|c|c|c|c|}
\hline $\begin{array}{l}\text { The thickness of the } \\
\text { base layer, } \mu \mathrm{m}\end{array}$ & $\begin{array}{c}J_{s c}, \\
\mathbf{m A} / \mathbf{c m}^{2}\end{array}$ & $\begin{array}{l}V_{o c}, \\
\mathbf{m V}\end{array}$ & FF & $\begin{array}{c}\text { Efficiency, } \\
\%\end{array}$ & $\begin{array}{c}J_{p}, \\
\mathbf{m A} / \mathbf{c m}^{2}\end{array}$ & $\begin{array}{c}R_{\text {sh }}, \\
\text { Ohm } \mathbf{c m}^{2}\end{array}$ & $\begin{array}{c}R_{s}, \\
\text { Ohm } \cdot \mathbf{c m}^{2} \\
\end{array}$ & $A$ & $\begin{array}{c}J_{0}, \\
\mathbf{A} / \mathbf{c m}^{2} \\
\end{array}$ \\
\hline 2,5 & 19,4 & 740 & 0,68 & 9,8 & 19,5 & 1,6 & 1031 & 2,28 & $6.2 \cdot 10^{-8}$ \\
\hline 1 & 19,3 & 670 & 0,52 & 6,7 & 19,7 & 4 & 185 & 3,03 & $3,0 \cdot 10^{-6}$ \\
\hline 0,8 & 19,1 & 607 & 0,51 & 5,9 & 19,2 & $<0,1$ & 169 & 4,11 & $4,9 \cdot 10^{-5}$ \\
\hline
\end{tabular}

As can be seen from the Tables 1, 2 with a thickness of less than $1 \mu \mathrm{m}$, a decrease in efficiency is observed not only during irradiation from the front, but also from the back. That is, it is impractical to create tandem and bilaterally sensitive PECs with tbl less than $1 \mu \mathrm{m}$. Therefore, to analyze the degradation stability, the ITO/CdS/CdTe/Cu/ITO PECs with tbl of $1 \mu \mathrm{m}$ were studied under illumination both from the back and from the front.

3. 2. The results of the study of the degradation stability of $\mathrm{ITO} / \mathrm{CdS} / \mathrm{CdTe} / \mathrm{Cu} / \mathrm{ITO}$ SCs with a base layer thickness of $1 \mu \mathrm{m}$

To analyze the degradation stability according to the method described in [2], ITO/ $\mathrm{CdS} / \mathrm{CdTe} / \mathrm{Cu} / \mathrm{ITO} \mathrm{SCs}$ with a base layer thickness of $1 \mu \mathrm{m}$ were studied under illumination 
from both the back and the front. The light CVCs of the structures under study are shown in Fig. 2.

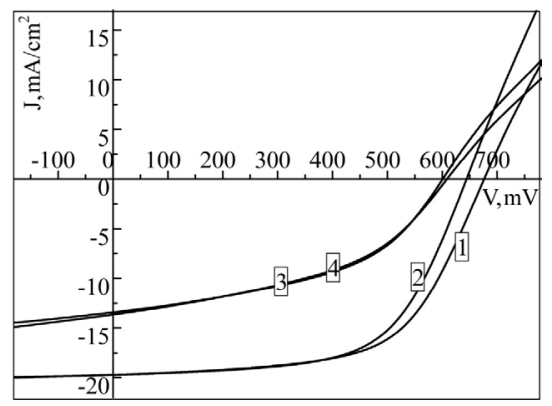

Fig. 2. Light CVCs of the ITO/CdS/CdTe/Cu/ITO PECs with $t_{b l} 1 \mu \mathrm{m}: 1$ - when irradiated from the front side for 1 year $2^{2}$ - when irradiated from the front side for 4.3 years; 3 - when irradiated from the back for 1 year 4 - when irradiated from the back for 4.3 years

The results of a study of the degradation stability of the ITO/CdS/CdTe/Cu/ITO PECs with $t_{b l}=1 \mu \mathrm{m}$ were obtained by analytical processing of the light CVCs (Fig. 2), the initial parameters and LDC were determined upon irradiation on both sides (Tables 3, 4).

Table 3

ITO/CdS/CdTe/Cu/ITO PECs output parameters and LDC with a base layer thickness of $1 \mu \mathrm{m}$ when irradiated from the front side

\begin{tabular}{|c|c|c|c|c|c|c|c|c|c|}
\hline $\begin{array}{l}\text { Time, } \\
\text { year }\end{array}$ & $\begin{array}{c}J_{s c}, \\
\mathbf{m A} / \mathbf{c m}^{2}\end{array}$ & $\begin{array}{l}V_{o c}, \\
\mathbf{m V}\end{array}$ & FF & $\begin{array}{c}\text { Efficiency, } \\
\%\end{array}$ & $\begin{array}{c}J_{\nu}, \\
\mathbf{m A} / \mathbf{c m}^{2}\end{array}$ & $\begin{array}{c}R_{s r}, \\
\mathrm{Ohm} \cdot \mathrm{cm}^{2}\end{array}$ & $\begin{array}{c}R_{s}, \\
\text { Ohm } \cdot \mathrm{cm}^{2}\end{array}$ & $A$ & $\begin{array}{c}J_{0}, \\
\mathbf{A} / \mathbf{c m}^{2}\end{array}$ \\
\hline 0 & 19,3 & 670 & 0,52 & 6,7 & 19,7 & 4 & 185 & 3 & $3,0 \cdot 10^{-6}$ \\
\hline 1 & 19,8 & 673 & 0,61 & 8,1 & 20,2 & 4 & 272 & 1,9 & $2,2 \cdot 10^{-8}$ \\
\hline 4,3 & 19,7 & 648 & 0,6 & 7,6 & 19,9 & 3,4 & 310 & 2,2 & $1,9 \cdot 10^{-7}$ \\
\hline
\end{tabular}

Table 4

ITO/CdS/CdTe/Cu/ITO PECs output parameters and LDC with a base layer thickness of $1 \mu \mathrm{m}$ when irradiated from the back side

\begin{tabular}{|c|c|c|c|c|c|c|c|c|c|}
\hline $\begin{array}{c}\boldsymbol{J}_{s c}, \\
\mathrm{~mA} / \mathbf{c m}^{2}\end{array}$ & $\begin{array}{l}V_{o c}, \\
\mathbf{m V}\end{array}$ & FF & $\begin{array}{c}\text { Efficiency, } \\
\%\end{array}$ & $\begin{array}{c}J_{p}, \\
\mathbf{m A} / \mathbf{c m}^{2}\end{array}$ & $\begin{array}{c}R_{\text {sh }}, \\
\text { Ohm } \cdot \mathrm{cm}^{2}\end{array}$ & $\begin{array}{c}R_{s}, \\
\text { Ohm } \cdot \mathrm{cm}^{2} \\
\end{array}$ & $\boldsymbol{A}$ & $\begin{array}{c}J_{0}, \\
\mathrm{~A} / \mathbf{c m}^{2}\end{array}$ & $\begin{array}{c}J_{s c}, \\
\mathrm{~mA} / \mathbf{c m}^{2}\end{array}$ \\
\hline 0 & 12,8 & 604 & 0,36 & 2,8 & 13,3 & 4,99 & 76,8 & 2,6 & $5,9 \cdot 10^{-7}$ \\
\hline 1 & 13,4 & 610 & 0,47 & 3,8 & 13,8 & 2,47 & 115 & 2,9 & $2,7 \cdot 10^{-6}$ \\
\hline 4,3 & 13,6 & 610 & 0,44 & 3,7 & 14,3 & 4,2 & 101 & 2,7 & $1,38 \cdot 10^{-6}$ \\
\hline
\end{tabular}

As can be seen from the Tables 3, 4, PECs with a base layer thickness of $1 \mu \mathrm{m}$ after a year of operation demonstrate maximum efficiency regardless of the direction of exposure.

\section{Discussion of the results of the study of the $\mathrm{ITO} / \mathrm{CdS} / \mathrm{CdTe} / \mathrm{Cu} / \mathrm{ITO}$ PECs with a decrease in the thickness of the base layer}

The initial parameters and light diode characteristics of receiving when illuminating the solar cells from the front side are shown in Table 1, showing that a decrease in $t_{b l}$ to $1 \mu \mathrm{m}$ leads to a decrease in the efficiency from $9.8 \%$ to $6.7 \%$, which is due to a decrease in $V_{o c}$ and the filling factor of the light CVCs. A decrease in the efficiency from $6.7 \%$ to $5.9 \%$ with a decrease in the layer thickness to $0.8 \mu \mathrm{m}$ is due to a decrease in $J_{s c}$ and $V_{o c}$ against the background of a constant value of the filling factor of the light CVCs. Modeling of the effect of a decrease in $t_{b l}$ from $2.5 \mu \mathrm{m}$ to $1 \mu \mathrm{m}$ on the global diode characteristics of solar cells and, accordingly, on efficiency, shows that an increase in $\mathrm{J} 0$ and a decrease in $R_{s}$ make a decisive contribution to the decrease in efficiency. The next decrease in $t_{b l}$ leads to a decrease in efficiency, which is mainly due to an increase in the diode saturation current. As the thickness of the base layer decreases, the area of the separating barrier approaches the surface of the back contact. 
Let's believe that the physical mechanism that causes the increase in $\mathrm{J} 0$ is the increase in the negative effect of surface recombination, as a result of which the effective life time of nonequilibrium charge carriers generated by light is reduced. In addition, with a decrease in the thickness of the cadmium telluride films, the space charge region may occupy the entire base layer and the thickness of the base layer is insufficient to ensure a complete drop in the contact potential difference arising at the boundary of the $\mathrm{CdS} / \mathrm{CdTe}$ structure. This fact causes a decrease in the potential difference in the region of the separating barrier and causes, which is observed experimentally, a decrease in $V_{o c}$. A decrease in $\mathrm{t}_{\mathrm{bl}}$ can lead to a decrease in $J_{s c}$ due to the fact that part of the radiation does not have time to absorb in the base layer and this leads to a decrease in the concentration of generated electron-hole pairs.

Parameters given in the Table 2 show the output parameters and the light-emitting diode characteristics of receiving when illuminating the solar cells from the back side, showing that when $t_{b l}$ decreases from $1 \mu \mathrm{m}$ to $0.8 \mu \mathrm{m}$, a change in efficiency is observed due to a decrease in shunt resistance. From our point of view, the non-monotonic change in the efficiency upon irradiation from the back with a decrease in the thickness of the base layer is due to the action of several competing physical mechanisms. A feature of photovoltaic processes during illumination on the back side is the spatial separation of the generation region of nonequilibrium carriers and their separation region by the built-in electric field of the separating barrier. When illuminated from the back, the generation region is located near the back surface, and the separation region is near the front. Therefore, as $t_{b l}$ decreases, the generation region approaches the separation region of nonequilibrium charge carriers. This leads to an experimentally observed increase in the photocurrent density, which causes an increase in efficiency with a decrease in thickness to $1 \mu \mathrm{m}$. Along with the described physical mechanism, a decrease in the thickness leads to a decrease in the lifetime of nonequilibrium charge carriers due to an increase in their recombination on the back surface. In this case, the height of the separating barrier also decreases and, obviously, the fraction of absorbed solar radiation decreases. It is with the action of these physical mechanisms that a decrease in the $\mathrm{SC}$ efficiency is associated with a decrease in the thickness of the base layer to $0.8 \mu \mathrm{m}$.

Noteworthy is the significant difference between the light diode characteristics during irradiation on both sides. For all thicknesses studied, the density of the saturation diode current is lower when illuminated from the back than from the front. This is due to the fact that under illumination from the back side near the separating barrier, fewer charge carriers are generated, and causes a decrease in $J_{0}$. Smaller shunt resistance values are due to the diode properties of the back contact, which is included in the opposite main separation barrier. In this case, the concentration of nonequilibrium charge carriers generated by light in the back contact region increases, which leads to a decrease in the size of the depletion region and a corresponding decrease in shunt resistance. With a decrease in the thickness of the base layer, the overlapping of the space charge regions of the main separation barrier and the back contact is enhanced, it can also lead to a decrease in the region of depletion of the back contact, and an experimental decrease in $\mathrm{R}_{\mathrm{s}}$ is observed when irradiated from both sides.

Analysis of the Table 3 shows that with an increase in the operating time of the ITO/CdS/ $\mathrm{CdTe} / \mathrm{Cu} / \mathrm{ITO} \mathrm{SCs}$ with $t_{b l}=1 \mu \mathrm{m}$ up to one year, an increase in efficiency is observed from $6.7 \%$ to $8.1 \%$, which is due to an increase in the filling factor of the light CVCs. Modeling of the effect of global diode characteristics on efficiency shows that an increase in shunt resistance makes a decisive contribution to the increase in efficiency. A further increase in operating time to 4.3 years is accompanied by a decrease in efficiency to $7.6 \%$. However, since the efficiency of PECs after 4 years remains above the initial value, the obtained PECs possess degradation stability necessary for practical use.

Analysis of the Table 4 shows that when irradiating from the back side, as well as when irradiating from the front, an increase in the operating time of the ITO/CdS/CdTe/Cu/ITO SCs with $t_{b l}=1 \mu \mathrm{m}$ to 1 year leads to an increase in efficiency from $2.8 \%$ to $3.8 \%$, which is due to an increase in the $\mathrm{FF}$ of the light $\mathrm{CVC}$. With a further increase in operating time up to 4.3 years, the efficiency decreases from $3.8 \%$ to $3.7 \%$, due to a decrease in the filling factor of the light CVC. Thus, all the qualitative trends in the change in the initial parameters and light diode characteristics when illuminating the ITO/CdS/CdTe/Cu/ITO PECs from the back and front sides are the same. 
Let's consider the possible physical mechanisms that determine the observed changes indicated above. In the ITO/CdS/CdTe/Cu/ITO PECs design, a nanoscale copper layer was deposited between the ITO layer and CdTe. The diffusion of copper in $t_{b l}$ of cadmium telluride is carried out along grain boundaries and grain volume. It is well known that the grain-boundary recombination rate is significantly higher than bulk recombination. When cadmium is replaced in the cadmium telluride lattice, copper atoms act as acceptors because they have a lower valency. Therefore, with grain-boundary diffusion, the electrical conductivity increases in the regions of CdTe adjacent to the grain boundaries. As a result of this, isotypic $\mathrm{p}-\mathrm{p}^{+}$transitions arise near the grain boundaries. Such $\mathrm{p}-\mathrm{p}^{+}$homojunctions reduce the recombination losses of nonequilibrium charge carriers generated by light due to the fact that when electrons approach the grain boundaries with their internal field, they push electrons into the bulk of the grain. Therefore, when copper is located in regions adjacent to grain boundaries, this leads to an increase in the lifetime of nonequilibrium charge carriers, and an increase in the lifetime leads to a decrease in the saturation diode current and a corresponding increase in the efficiency of the device structure. Thus, the physical mechanism for decreasing the saturation diode current density with an increase in operating time up to 1 year is described in particular in ITO/CdS/CdTe/Cu/ITO PECs.

Since diffusion over the volume of grain is slow, a decrease in the concentration of copper on the grain-boundary surface due to its escape into the volume of grain due to the presence of a concentration gradient becomes significant for sufficiently long periods of operation of the solar cells. An increase in the concentration of copper in the grain volume leads to an increase in conductivity and a decrease in the height of potential barriers of the above isotypic homojunctions. This, in turn, causes an increase in grain-boundary recombination and leads to a fixed increase in the density of the diode saturation current, and an experimental decrease in the efficiency is observed.

The shunt resistance $R_{s h}$ is included in the equivalent photomultiplier to take into account the influence on the efficiency of photoelectric processes of low electrical support of local parts of the device structure, such as: end surfaces, grain boundaries, secondary phases, through pores in the layers. In the framework of the traditional equivalent PEC scheme, the observed evolution of shunt resistance can't be explained.

Thus, when conducting further studies of PECs based on cadmium telluride assigned to tandem and two-sided sensitive solar cells, the main attention should be focused on ways to limit the diffusion of copper into the grain volume, and not on further reducing the thickness of the base layer. Since a further decrease in the thickness of the base layer leads to a decrease in the diode characteristics and, accordingly, the output parameters of the solar cell.

\section{Conclusions}

When studying the ITO/CdS/CdTe/Cu/ITO PECs, it was found that a decrease in the thickness of the base layer to $1 \mu \mathrm{m}$ makes it possible to increase the efficiency of the instrument structure from $2.8 \%$ to $3.8 \%$ when illuminated from the back due to the approximation of the region of active generation of nonequilibrium carriers charge in the field of separation.

With a base layer thickness of less than $1 \mu \mathrm{m}$, regardless of the direction of illumination, a decrease in efficiency is observed from $6.7 \%$ to $5.9 \%$ when irradiated from the front, and from $2.8 \%$ to $1.5 \%$ when irradiated from the back, due to an increase in the negative the effect of surface recombination on the back contact, a decrease in the number of charge carriers generated due to incomplete absorption of the incident radiation, and a decrease in the built-in field of the separating barrier when it overlaps with the depletion region of the back contact.

ITO/CdS/CdTe/Cu/ITO PECs with a base layer thickness of $1 \mu \mathrm{m}$ demonstrate high degradation stability. The maximum efficiency when lighting from the front side is $8.1 \%$ and when lighting from the back side is $3.8 \%$ after a year of operation of the devices of the structure.

\section{References}

[1] Khrypunov, G., Vambol, S., Deyneko, N., Sychikova, Y. (2016). Increasing the efficiency of film solar cells based on cadmium telluride. Eastern-European Journal of Enterprise Technologies, 6 (5 (84)), 12-18. doi: https://doi.org/10.15587/17294061.2016.85617 
[2] Deyneko, N., Kovalev, P., Semkiv, O., Khmyrov, I., Shevchenko, R. (2019). Development of a technique for restoring the efficiency of film ITO/CdS/CdTe/Cu/Au SCs after degradation. Eastern-European Journal of Enterprise Technologies, 1 (5 (97)), 6-12. doi: https://doi.org/10.15587/1729-4061.2019.156565

[3] Lunin, L. S., Lunina, M. L., Pashchenko, A. S., Alfimova, D. L., Arustamyan, D. A., Kazakova, A. E. (2019). Cascade Solar Cells Based on GaP/Si/Ge Nanoheterostructures. Technical Physics Letters, 45 (3), 250-252. doi: https://doi.org/10.1134/ s1063785019030313

[4] Khrypunov, G. S., Sokol, E. I., Yakimenko, Yu. I., Meriuts, A. V., Ivashuk, A. V., Shelest, T. N. (2014). Conversion of solar energy by combination solar cells based on CdTe and CuInSe $\square$. Fizika i tehnika poluprovodnikov, 48 (12), 1671-1675.

[5] De Vos, A., Parrott, J., Baruch, P., Landsberg, P. (1994). Bandgap effects in thin-film heterojunction solar cells. Proceeding 12th European Photovoltaic Solar Energy Conference. Amsterdam, 1315-1319.

[6] Gordillo, G., Calderón, C., Bolaños, W., Romero, E. (2003). Optical and structural characterization of CuInSe2 (CIS) thin films grown by means of process in two stages. Superficies y Vacio, 16 (2), 12-15.

[7] Khrypunov, G., Meriuts, A., Klochko, H., Shelest, T., Khrypunova, A. (2010). Investigation of Thin Film Solar Cells on CdS/ CdTe Base with Different Back Contacts. Advances in Science and Technology, 74, 119-123. doi: https://doi.org/10.4028/www. scientific.net/ast.74.119

[8] Kuprikov, V. I., Pilipenko, V. V., Soznik, A. P. (2006). Analysis of nucleon-nucleus scattering in terms of a microscopic optical potential based on effective Skyrme forces. Physics of Atomic Nuclei, 69 (1), 6-15. doi: https://doi.org/10.1134/ s1063778806010029

[9] Deyneko, N., Semkiv, O., Soshinsky, O., Streletc, V., Shevchenko, R. (2018). Results of studying the Cu/ITO transparent back contacts for solar cells SnO2:F/CdS/CdTe/Cu/ITO. Eastern-European Journal of Enterprise Technologies, 4 (5 (94)), 29 -34. doi: https://doi.org/10.15587/1729-4061.2018.139867

[10] Deyneko, N., Semkiv, O., Khmyrov, I., Khryapynskyy, A. (2018). Investigation of the combination of ITO/CdS/CdTe/Cu/Au solar cells in microassembly for electrical supply of field cables. Eastern-European Journal of Enterprise Technologies, 1 (12 (91)), 18-23. doi: https://doi.org/10.15587/1729-4061.2018.124575

[11] Hripunov, G. S., Boyko, B. T. (2004). Flexible ITO/CdS/CdTe/Cu/Au solar cells with high specific capacity. PSE, 2 (1-2), 69-73.

[12] Mamazza, R., Balasubramanian, U., More, D. L., Ferekides, C. S. (2002). Thin films of $\mathrm{CdIn}_{2} \mathrm{O}_{4}$ as transparent conducting oxides. Conference Record of the Twenty-Ninth IEEE Photovoltaic Specialists Conference, 2002. doi: https://doi.org/10.1109/ pvsc. 2002.1190640

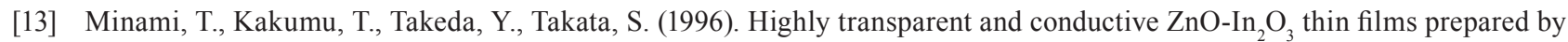
d.c. magnetron sputtering. Thin Solid Films, 290-291, 1-5. doi: https://doi.org/10.1016/s0040-6090(96)09094-3

[14] Venkatesan, M., Gee, S., Mitra, U. (1989). Indium tin oxide for metallization in microelectronic device. Thin Solid Film, 170, 151-162.

[15] Jeong, W.-J., Park, G.-C. (2001). Electrical and optical properties of ZnO thin film as a function of deposition parameters. Solar Energy Materials and Solar Cells, 65 (1-4), 37-45. doi: https://doi.org/10.1016/s0927-0248(00)00075-1

[16] Karpov, V. G., Shvydka, D., Roussillon, Y. (2004). E2phase transition: Thin-film breakdown and Schottky-barrier suppression. Physical Review B, 70 (15). doi: https://doi.org/10.1103/physrevb.70.155332

[17] Razykov, T. M., Ferekides, C. S., Morel, D., Stefanakos, E., Ullal, H. S., Upadhyaya, H. M. (2011). Solar photovoltaic electricity: Current status and future prospects. Solar Energy, 85 (8), 1580-1608. doi: https://doi.org/10.1016/j.solener.2010.12.002

[18] Fang, Z., Wang, X. C., Wu, H. C., Zhao, C. Z. (2011). Achievements and Challenges of CdS/CdTe Solar Cells. International Journal of Photoenergy, 2011, 1-8. doi: https://doi.org/10.1155/2011/297350 